\title{
Bactericidal Effects of Diode Laser Irradiation on Enterococcus faecalis Using Periapical Lesion Defect Model
}

\author{
Masato Nagayoshi, ${ }^{1}$ Tatsuji Nishihara, ${ }^{2}$ Keisuke Nakashima, ${ }^{3}$ Shigetsugu Iwaki, ${ }^{4}$ \\ Ker-Kong Chen, ${ }^{5}$ Masamichi Terashita, ${ }^{6}$ and Chiaki Kitamura ${ }^{1}$ \\ ${ }^{1}$ Division of Pulp Biology, Operative Dentistry, and Endodontics, Department of Cariology and Periodontology, \\ Kyushu Dental College, 2-6-1 Manazuru, Kokurakita, Kitakyushu 803-8580, Japan \\ ${ }^{2}$ Division of Infections and Molecular Biology, Department of Health Promotion, Kyushu Dental College, 2-6-1 Manazuru, \\ Kokurakita, Kitakyushu 803-8580, Japan \\ ${ }^{3}$ Division of Periodontology, Department of Cariology and Periodontology, Kyushu Dental College, 2-6-1 Manazuru, \\ Kokurakita, Kitakyushu 803-8580, Japan \\ ${ }^{4}$ Marketing Research Section, ReD Department, NISSIN DENTAL PRODUCTS INC., 22-1 miyabayashi, asahi, Kameoka, \\ Kyoto 621-0001, Japan \\ ${ }^{5}$ Department of Conservative Dentistry, Kaohsiung Medical University Hospital and College of Dental Medicine, \\ Kaohsiung Medical University, Shih-Chuan 1st Road, Kaohsiung 80708, Taiwan \\ ${ }^{6}$ Division of Comprehensive Dentistry, Department of Clinical Communication and Practice, Kyushu Dental College, \\ 2-6-1 Manazuru, Kokurakita, Kitakyushu 803-8580, Japan
}

Correspondence should be addressed to Chiaki Kitamura, chi-aki-k@kyu-dent.ac.jp

Received 13 May 2011; Accepted 19 June 2011

Academic Editor: A. Carrassi

Copyright ( $) 2011$ Masato Nagayoshi et al. This is an open access article distributed under the Creative Commons Attribution License, which permits unrestricted use, distribution, and reproduction in any medium, provided the original work is properly cited.

\begin{abstract}
Objective. Photodynamic therapy has been expanded for use in endodontic treatment. The aim of this study was to investigate the antimicrobial effects of diode laser irradiation on endodontic pathogens in periapical lesions using an in vitro apical lesion model. Study Design. Enterococcus faecalis in $0.5 \%$ semisolid agar with a photosensitizer was injected into apical lesion area of in vitro apical lesion model. The direct effects of irradiation with a diode laser as well as heat produced by irradiation on the viability of microorganisms in the lesions were analyzed. Results. The viability of E. faecalis was significantly reduced by the combination of a photosensitizer and laser irradiation. The temperature caused by irradiation rose, however, there were no cytotoxic effects of heat on the viability of E. faecalis. Conclusion. Our results suggest that utilization of a diode laser in combination with a photosensitizer may be useful for clinical treatment of periapical lesions.
\end{abstract}

\section{Introduction}

It is generally accepted that disinfecting processes are essential for successful root canal treatment, and antimicrobial irrigants to remove microorganisms are important for chemomechanical preparation of a root canal $[1,2]$. Endodontic irrigants are required to have a broad spectrum of antimicrobial activities, as well as a relative lack of toxicity against sound periapical tissue. Sodium hypochlorite $(\mathrm{NaOCl})$ is a major endodontic irrigant, however, it has cytotoxic and neurotoxic effects when extruded into periapical tissues $[3,4]$. To develop a safe endodontic irrigants, ozonated water was previously examined as an endodontic irrigant and demonstrated to be a useful irrigant for removal of microorganisms from root canals without damage to other tissues [5]. However, it is also known that complete elimination of microorganisms from root canals and periapical lesions by antimicrobial irrigants only is difficult, because of the anatomical complexities of root canals, deep invasion of microorganisms into dentinal tubules, and formation of biofilms on the surface of root apex, resulting in persistent apical periodontitis [6-8]. In addition, several studies have reported that the lack of response of refractory periapical lesion is due to the in inaccessibility of the extraradicular microorganisms or to the presence of microorganisms [9$11]$. 


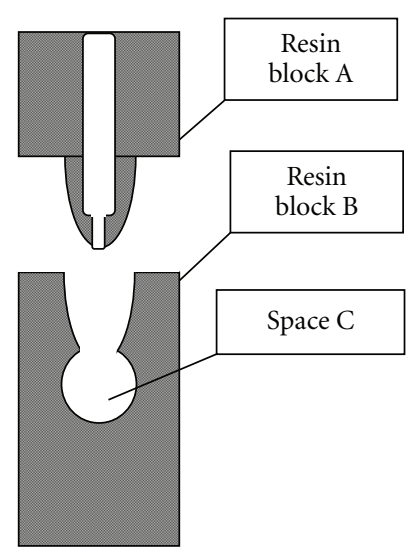

FIGURE 1: Schematic representation of present in vitro model of apical periodontitis. Resin block A, root part with a single root canal with an apical foramen (diameter $600 \mu \mathrm{m}$ ). Resin block B, periapical tissue portion with a space (Space $\mathrm{C}$, diameter $5 \mathrm{~mm}$ ) fashioned as a periapical lesion defect.

Recently, photodynamic antimicrobial chemotherapy has received focus as an alternate antibacterial, antifungal, and antiviral treatment for drug-resistant microorganisms [12, 13]. Along that line, disinfection of root canals by laser irradiation has been demonstrated [14-16]. When using laser irradiation for disinfection of root canals and periapical lesions, damage to periapical tissues by heat produced by the irradiation procedure should be avoided [17-19]. Several studies have reported the antimicrobial effectiveness and safety of laser irradiation of root canals. However, there are no known reports regarding the antimicrobial effects of laser irradiation on microorganisms in periapical lesions without corresponding heat damage to sound periapical tissues, because of difficulties in mimicking the related environment.

A few studies have reported that use of a photosensitizer in combination with laser irradiation was effective for selective elimination of microorganisms from root canals and periapical lesions [20-22]. The aim of this study was to investigate the antimicrobial effects of diode laser irradiation in combination with a photosensitizer against Enterococcus faecalis, one of the major organisms related to persistent apical periodontitis $[10,11,23,24]$ in periapical lesions using an in vitro apical lesion model. In addition, irradiationinduced heat changes and the effects of heat on E. faecalis were examined using our periapical lesion model.

\section{Material and Methods}

2.1. Light Source and Photosensitizer. The irradiation source was a diode laser (P-Laser; Panasonic Dental Co., Ltd., Osaka, Japan). Its wavelength, output power, and duty were $805 \mathrm{~nm}$, 5 watts (W), and $20 \%$, respectively, while the diameter of quartz optical fiber was $400 \mu \mathrm{m}$. Indocyanine green (Opthagreen ${ }^{\circledR}$; Santen Pharmaceutical Co., Ltd., Osaka, Japan) $(12.5 \mathrm{mg} / \mathrm{mL})$, a commonly used fluorescent fundus contrast medium, was used as the photosensitizer.

2.2. Antimicrobial Activity of Laser Irradiation. E. faecalis ATCC 29212 was cultured in brain-heart infusion (BHI) broth (Difco, Detroit, $\mathrm{MI}$ ) at $37^{\circ} \mathrm{C}$ for 18 hours in an atmosphere of $5 \% \mathrm{CO}_{2}$. The organisms were harvested by centrifugation at $10,000 \times \mathrm{g}$ for 5 minutes then suspended in saline and adjusted to $3 \times 10^{6}$ cells/mL using a spectrophotometer. Bacterial cell suspensions were mixed with sterilized saline or indocyanine green solution in sterilized test tubes for a final suspension of $1.5 \times 10^{6}$ cells $/ \mathrm{mL}$, then individually irradiated by the diode laser at a distance of $1 \mathrm{~mm}$ for 30 , 60 , or 120 seconds. Following irradiation, each suspension ( $20 \mu \mathrm{L}$ including $3 \times 10^{2}$ cells) was cultured on a BHI agar plate. The inoculated plates were incubated at $37^{\circ} \mathrm{C}$ for 18 hours in an atmosphere of $5 \% \mathrm{CO}_{2}$ and colony-forming units (CFU) counted using the spread plate method.

\subsection{Laser Irradiation Using In Vitro Model of Periapical Lesion} Defect. An in vitro model of a periapical lesion defect was fashioned from resin blocks (Nissin Dental Products, Inc., Kyoto, Japan) (Figure 1). It was made up of a single root canal with an apical foramen (diameter; $600 \mu \mathrm{m}$ ) in resin block $A$, which formed the root part of the model, while resin block $\mathrm{B}$, which was used as the periapical tissue portion, had a space (Space $C$, diameter; $5 \mathrm{~mm}$ ) fashioned as a periapical lesion defect. The model was sterilized before each experiment. E. faecalis was diluted to $2 \times 10^{6}$ cells $/ \mathrm{mL}$ with prewarmed $\left(45^{\circ} \mathrm{C}\right) \mathrm{BHI}$ broth containing $1 \%$ agar, then $20 \mu \mathrm{L}$ of the bacterial cell suspension was mixed with $20 \mu \mathrm{L}$ of distilled saline or indocyanine green solution in Space C (final concentration of E. faecalis, $1 \times 10^{6}$ cells $/ \mathrm{mL}$ ). Resin block $\mathrm{A}$ was then inserted into resin block B and kept at room temperature.

The optical fiber of the diode laser was inserted into the root canal to reach its apex then microorganisms in Space C were irradiated for 30, 60, or 120 seconds. In addition, the model was also irrigated with sterilized saline $(4 \mathrm{~mL})$ or $2.5 \% \mathrm{NaOCl}(4 \mathrm{~mL})$ for 120 seconds as negative and positive controls, respectively. After each treatment, E. faecalis in Space C were diluted 1/100 with sterilized saline and subjected to vortexing for 5 minutes, then $20 \mu \mathrm{L}$ of each sample $\left(2 \times 10^{2}\right.$ cells $)$ was cultured on a BHI agar plate. CFU were determined after incubation of the inoculated plates at $37^{\circ} \mathrm{C}$ for 18 hours in an atmosphere of $5 \% \mathrm{CO}_{2}$.

2.4. Exposure of Microorganisms to Heat. E. faecalis suspensions were mixed with a sterilized indocyanine green solution (final suspension $1.5 \times 10^{6}$ cells $/ \mathrm{mL}$ ) and incubated in a heat block (TERMO ALUMI BATH ALB-220: IWAKI GLASS Co., Ltd. Japan) at $65^{\circ} \mathrm{C}$ for 60 seconds, after which heat-treated E. faecalis $\left(20 \mu \mathrm{L} ; 3 \times 10^{2}\right.$ cells $)$ were cultured on BHI agar plates. The inoculated plates were then incubated at $37^{\circ} \mathrm{C}$ for 18 hours in an atmosphere of $5 \% \mathrm{CO}_{2}$ in air and $\mathrm{CFU}$ determined.

2.5. Temperature Monitoring during Laser Irradiation. Temperatures in the periapical lesion (Space C) and surrounding areas of the in vitro model were monitored during laser irradiation using infrared thermography (TH9100 WV: NEC Avio Infrared Technologies Co., Ltd. Japan). Just after performing laser irradiation, the inner temperature of the periapical lesion area (Space C) was also measured 


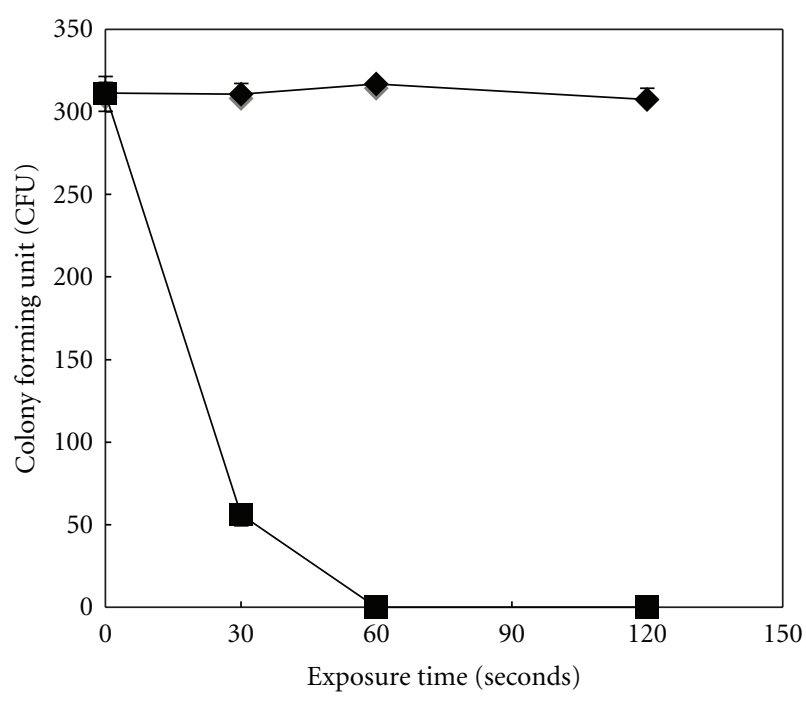

(A)

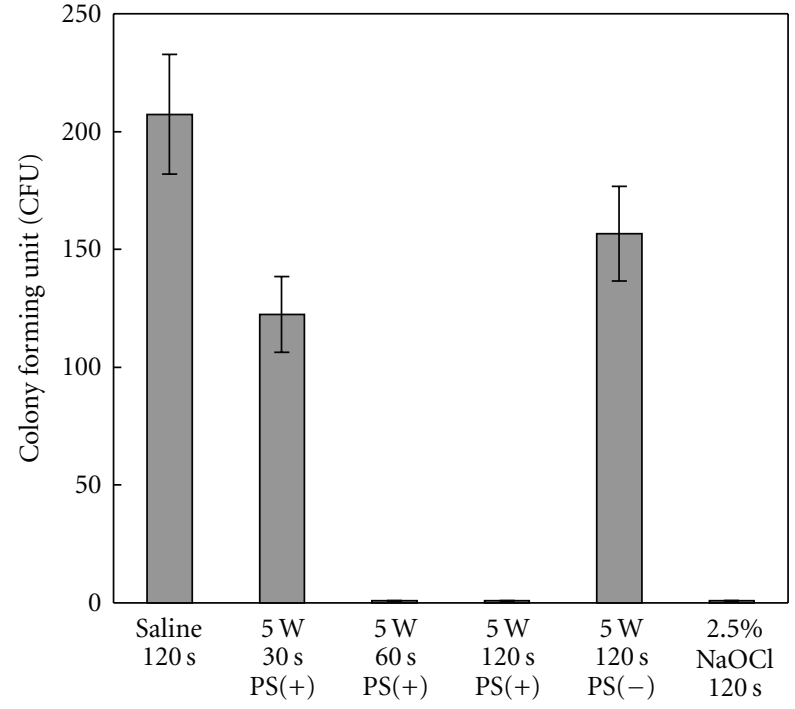

(B)

Figure 2: Antimicrobial effects of diode laser on E. faecalis in test tubes. The bacteria were exposed to laser irradiation with or without an added photosensitizer (closed diamond, without photosensitizer; closed square, with photosensitizer) for 30, 60, and 120 seconds. (A) Elimination of E. faecalis in model of apical periodontitis. E. faecalis in the presence and absence of a photosensitizer[PS(-), without photosensitizer; PS(+), with photosensitizer] in the lesion defect area of the model were exposed to diode laser irradiation for 30, 60, and 120 seconds. In addition, one sample was irrigated with sterilized saline for 120 seconds as a negative control (saline- $120 \mathrm{~s}$ ) and another with $2.5 \% \mathrm{NaOCl}$ for 120 seconds as a positive control (2.5\% NaOCl-120 s). (B) The number of viable cells after each treatment was counted. Data are expressed as the mean \pm standard deviation of triplicate determinations. The experiment was performed three times, with similar results obtained in each.

by immediate insertion of a thermocouple thermometer (Digital Thermometer CT-800: As One Corp., Japan).

2.6. Statistical Analysis. Differences among variables in the experiments were compared using Student's $t$-test.

\section{Results}

\subsection{Antimicrobial Effects of Diode Laser with Photosensitizer} and Disinfection of Periapical Lesion Defect in In Vitro Model. There were no antimicrobial effects seen without the photosensitizer, whereas in its presence the cell viability of $E$. faecalis decreased to $72 \%$ after irradiation for 30 seconds and was not detected after irradiation of 60 seconds or more in test tubes (Figure 2(A)).

Figure 2(B) shows the antimicrobial effects of diode laser irradiation on $E$. faecalis in the in vitro model. Irrigation with saline did not have an antimicrobial effect, while that with $\mathrm{NaOCl}$ completely eliminated E. faecalis. When the diode laser was used without the photosensitizer for 120 seconds, the decrease in viability was only $25 \%$. In contrast, a significant decrease in the viability of $E$. faecalis was observed following laser irradiation with the photosensitizer for 60 and 120 seconds.

\subsection{Effects of Heat Produced by Laser Irradiation on Bacterial} Cell Viability. The inner temperature of the apical lesion area of the in vitro model was determined with a thermocouple thermometer just after laser irradiation (Figure 3(A)). Irradiation for 60 seconds increased the temperature of the periapical lesion defect to $65^{\circ} \mathrm{C}$. To analyze the cytotoxic effects of that elevated temperature $\left(65^{\circ} \mathrm{C}\right)$ on $E$. faecalis, bacterial cells were incubated in a heat block at $65^{\circ} \mathrm{C}$ for 60 seconds (Figure 3(B)). There was no effect on bacterial cell viability by exposure to heating at $65^{\circ} \mathrm{C}$, whereas the viability was significantly reduced when the bacterial cells were irradiated for 60 seconds in the presence of the photosensitizer. The rise in temperature in the periapical lesion and surrounding area of the in vitro model during laser irradiation was monitored using a thermotracer (Figure 3(C)). There was no change in temperature in either the lesion or surrounding area caused by irradiation when the photosensitizer was not added to the bacterial cell suspension (Figures 3(D)-3(F)). However, the thermotracer indicated an increase in temperature in the periapical lesion area with addition of the photosensitizer (Figures $3(\mathrm{G})-3(\mathrm{I})$ ), which was $2^{\circ} \mathrm{C}$ after irradiation for 60 seconds and $6^{\circ} \mathrm{C}$ after that for 120 seconds (Figure $3(\mathrm{~J})$ ). In contrast, there was no rise in temperature observed in the area surrounding the lesion area even with addition of the photosensitizer (Figures $3(\mathrm{G})-3(\mathrm{I})$ ).

\section{Discussion}

It is known that various photosensitizers are taken up by tumor cells and microorganisms, and those activated by laser irradiation interact with oxygen to produce radical species that have a toxic effect on those cells and microorganisms [25]. In the present study, indocyanine green, which was a photosensitizer commonly used as fluorescent fundus contrast medium that does not have toxicity toward surrounding tissues, increased the antimicrobial effects of laser irradiation 


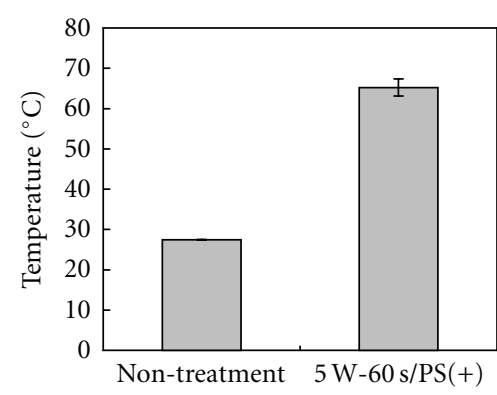

(A)

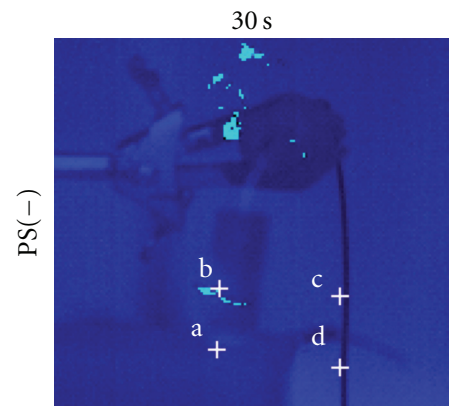

(D)

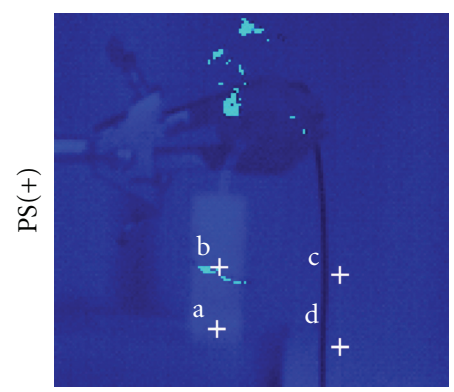

(G)

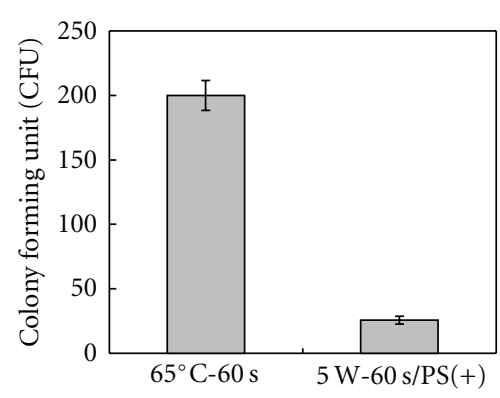

(B)

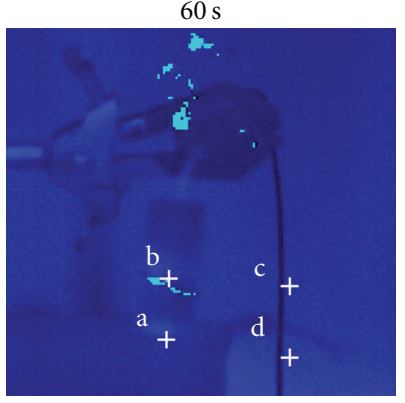

(E)

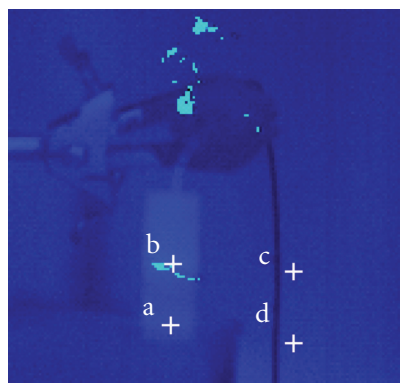

$(\mathrm{H})$

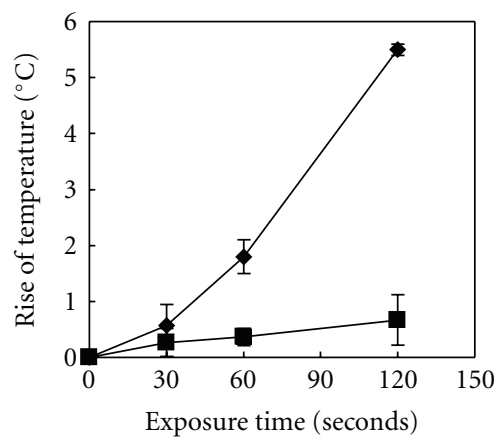

(J)

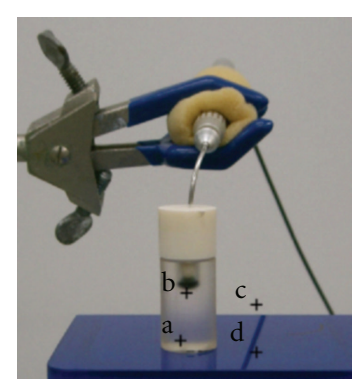

(C)

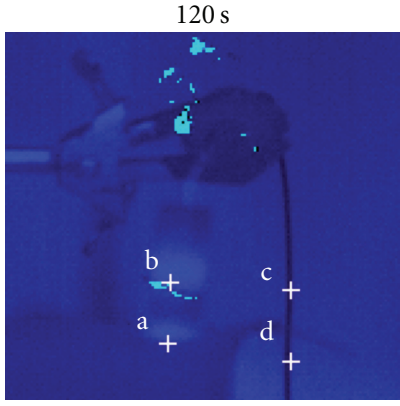

(F)

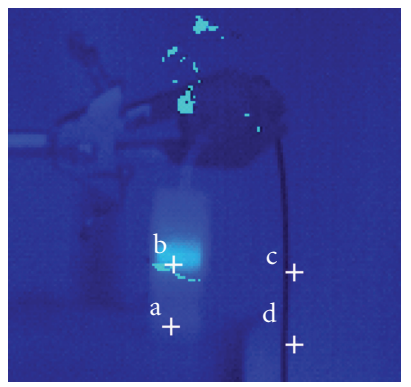

(I)

Figure 3: Effects of heat produced by laser irradiation. (A) Change of inner temperature in apical lesion area of in vitro model following laser irradiation. (B) Antimicrobial effects of heat on E. faecalis. The microorganisms were exposed to diode laser irradiation in the presence of a photosensitizer for 60 seconds [ $5 \mathrm{~W}-60 \mathrm{~s} / \mathrm{PS}(+)$ ] or exposed to heat at $65^{\circ} \mathrm{C}$ for 60 seconds $\left(65^{\circ} \mathrm{C}-60 \mathrm{~s}\right)$. (C). Photograph of temperature change monitoring using a thermotracer, which was used to monitor 4 points ( $a, b, c, d)$ of the in vitro model. (D-F). Temperature change without photosensitizer. (G-I). Temperature change with photosensitizer. (J) Temperature change in periapical lesion area of the model during irradiation (closed diamond, with photosensitizer; closed square, without photosensitizer). The rise in temperature was calculated as the difference in temperature between points a and $b$. Data are expressed as the mean \pm standard deviation of triplicate determinations. The experiment was performed three times, with similar results obtained in each. 
in test tubes. However, that environment is different from that of a periapical lesion, which is surrounded by sound periapical tissues, and it takes many efforts to make a standardized apical lesion model in vivo.

To simulate biological conditions, we prepared an in vitro apical lesion model and examined the antimicrobial effects of diode laser irradiation with or without the addition of a photosensitizer. When a bacterial cell suspension with indocyanine green was irradiated with the diode laser using periapical lesion model, E. faecalis CFU were significantly decreased to the same amount following irrigation with $\mathrm{NaOCl}$. In a study of bactericidal activity against E. faecalis biofilm in extracted human teeth, it was reported that the total energy output of a diode laser was 36J [26]. In the present study, an irradiation time of 60 seconds was employed to achieve a total energy level of 76J and that with an added photosensitizer was adequate for a high level of sterilization. On the other hand, application of the present diode laser for 60 seconds increased the temperature of the lesion area to $65^{\circ} \mathrm{C}$. However, exposure of E. faecalis to $65^{\circ} \mathrm{C}$ for 60 seconds in a heat block did not have any effects on bacterial viability. These results indicate that the reduction in viability of $E$. faecalis was from the laser irradiation itself, not from the heat produced by the irradiation, and that addition of a photosensitizer is essential for the observed antimicrobial effects.

Adverse effects of intense heat produced by laser irradiation on sound periapical tissues are a concern in clinical applications. It has been reported that use of a diode laser resulted in the least amount of temperature increase among several types of lasers tested [19]. In the present study, it was found that irradiation at $5 \mathrm{~W}$ for 60 seconds in the presence of a photosensitizer raised it by $2{ }^{\circ} \mathrm{C}$ in the lesion defect area, whereas no change in temperature was observed in the surrounding area. Furthermore, it has been demonstrated that the same diode laser irradiation with various levels of laser power $(0.5 \mathrm{~W}$ to $5 \mathrm{~W})$ for 2 minutes did not affect proliferation of mammalian cells in vitro and enhanced BMP-induced osteoblast differentiation by stimulating BMP/Smad signaling pathway [27]. Taken together, the present laser technique, which was adequate for elimination of E. faecalis, may have no cytotoxic effects on sound periapical tissues.

In conclusion, diode laser irradiation in combination with a photosensitizer had nearly the same antimicrobial effect as $2.5 \% \mathrm{NaOCl}$. Many clinicians prefer a diluted concentration to reduce the irritation potential of $\mathrm{NaOCl}$, with $2.5 \%$ commonly recommended [28]. However, fibroblasts were found damaged by $2.5 \% \mathrm{NaOCl}[3,5,28-30]$. The present results indicated no cytotoxic effects from heat produced by laser irradiation, thus use of a diode laser with a photosensitizer is useful for treatment of periapical lesions without adverse effects on surrounding tissues. This standardized in vitro apical lesion model needs more improvement, but it may be useful for an endodontic study.

\section{Acknowledgments}

This investigation was supported in part by a Grant-inAid for Scientific Research (21592428) from The Ministry of Education, Culture, Sports, Science and Technology of Japan.

\section{References}

[1] T. W. Chow, "Mechanical effectiveness of root canal irrigation," Journal of Endodontics, vol. 9, no. 11, pp. 475-479, 1983.

[2] J. F. Siqueira Jr., I. N. Rôças, S. R. Santos, K. C. Lima, F. A. Magalhães, and M. de Uzeda, "Efficacy of instrumentation techniques and irrigation regimens in reducing the bacterial population within root canals," Journal of Endodontics, vol. 28, no. 3, pp. 181-184, 2002.

[3] A. Gatot, J. Arbelle, A. Leiberman, and I. Yanai-Inbar, "Effects of sodium hypochlorite on soft tissues after its inadvertent injection beyond the root apex," Journal of Endodontics, vol. 17, no. 11, pp. 573-574, 1991.

[4] E. J. Neaverth and R. Swindle, "A serious complication following the inadvertent injection of sodium hypochlorite outside the root canal system," Compendium, vol. 11, no. 8, pp. 474-481, 1990.

[5] M. Nagayoshi, C. Kitamura, T. Fukuizumi, T. Nishihara, and M. Terashita, "Antimicrobial effect of ozonated water on bacteria invading dentinal tubules," Journal of Endodontics, vol. 30, no. 11, pp. 778-781, 2004.

[6] N. Noguchi, Y. Noiri, M. Narimatsu, and S. Ebisu, "Identification and localization of extraradicular biofilm-forming bacteria associated with refractory endodontic pathogens," Applied and Environmental Microbiology, vol. 71, no. 12, pp. 8738-8743, 2005.

[7] Y. Noiri, A. Ehara, T. Kawahara, N. Takemura, and S. Ebisu, "Participation of bacterial biofilms in refractory and chronic periapical periodontitis," Journal of Endodontics, vol. 28, no. 10, pp. 679-683, 2002.

[8] F. J. Vertucci, "Root canal anatomy of the human permanent teeth," Oral Surgery Oral Medicine and Oral Pathology, vol. 58, no. 5, pp. 589-599, 1984.

[9] R. Fujii, Y. Saito, Y. Tokura, K. I. Nakagawa, K. Okuda, and K. Ishihara, "Characterization of bacterial flora in persistent apical periodontitis lesions," Oral Microbiology and Immunology, vol. 24 , no. 6, pp. 502-505, 2009.

[10] K. Subramanian and A. K. Mickel, "Molecular analysis of persistent periradicular lesions and root ends reveals a diverse microbial profile," Journal of Endodontics, vol. 35, no. 7, pp. 950-957, 2009.

[11] P. T. Sunde, I. Olsen, G. J. Debelian, and L. Tronstad, "Microbiota of periapical lesions refractory to endodontic therapy," Journal of Endodontics, vol. 28, no. 4, pp. 304-310, 2002.

[12] M. Wainwright, "Photodynamic antimicrobial chemotherapy (PACT)," Journal of Antimicrobial Chemotherapy, vol. 42, no. 1, pp. 13-28, 1998.

[13] M. Wainwright and K. B. Crossley, "Photosensitising agentscircumventing resistance and breaking down biofilms: a review," International Biodeterioration and Biodegradation, vol. 53, no. 2, pp. 119-126, 2004.

[14] E. B. de Souza, S. Cai, M. R.L. Simionato, and J. L. LageMarques, "High-power diode laser in the disinfection in depth of the root canal dentin," Oral Surgery, Oral Medicine, Oral Pathology, Oral Radiology and Endodontology, vol. 106, no. 1, pp. e68-e72, 2008.

[15] J. A. Williams, G. J. Pearson, and M. John Colles, "Antibacterial action of photoactivated disinfection $\{\mathrm{PAD}\}$ used on endodontic bacteria in planktonic suspension and in artificial 
and human root canals," Journal of Dentistry, vol. 34, no. 6, pp. 363-371, 2006.

[16] L. Zhu, M. Tolba, D. Arola, M. Salloum, and F. Meza, "Evaluation of effectiveness of Er,Cr:YSGG laser for root canal disinfection: theoretical simulation of temperature elevations in root dentin," Journal of Biomechanical Engineering, vol. 131, no. 7, Article ID 710041, 2009.

[17] M. Kreisler, W. Kohnen, M. Beck et al., "Efficacy of $\mathrm{NaOCl} / \mathrm{H}_{2} \mathrm{O}_{2}$ irrigation and $\mathrm{GaAlAs}$ laser in decontamination of root canals in vitro," Lasers in Surgery and Medicine, vol. 32, no. 3, pp. 189-196, 2003.

[18] U. Schoop, W. Kluger, S. Dervisbegovic et al., "Innovative wavelengths in endodontic treatment," Lasers in Surgery and Medicine, vol. 38, no. 6, pp. 624-630, 2006.

[19] U. Schoop, W. Kluger, A. Moritz, N. Nedjelik, A. Georgopoulos, and W. Sperr, "Bactericidal effect of different laser systems in the deep layers of dentin," Lasers in Surgery and Medicine, vol. 35, no. 2, pp. 111-116, 2004.

[20] J. L. Fimple, C. R. Fontana, F. Foschi et al., "Photodynamic treatment of endodontic polymicrobial infection in vitro," Journal of Endodontics, vol. 34, no. 6, pp. 728-734, 2008.

[21] A. Silva Garcez, S. C. Núñez, J. L. Lage-Marques, A. O. C. Jorge, and M. S. Ribeiro, "Efficiency of $\mathrm{NaOCl}$ and laser-assisted photosensitization on the reduction of Enterococcus faecalis in vitro," Oral Surgery, Oral Medicine, Oral Pathology, Oral Radiology and Endodontology, vol. 102, no. 4, pp. e93-e98, 2006.

[22] N. S. Soukos, P. S. Y. Chen, J. T. Morris et al., "Photodynamic therapy for endodontic disinfection," Journal of Endodontics, vol. 32, no. 10, pp. 979-984, 2006.

[23] R. M. Love, "Enterococcus faecalis—a mechanism for its role in endodontic failure," International Endodontic Journal, vol. 34, no. 5, pp. 399-405, 2001.

[24] I. N. Rôças, J. F. Siqueira Jr., and K. R. N. Santos, "Association of Enterococcus faecalis with different forms of periradicular diseases," Journal of Endodontics, vol. 30, no. 5, pp. 315-320, 2004.

[25] K. Konopka and T. Goslinski, "Photodynamic therapy in dentistry," Journal of Dental Research, vol. 86, no. 8, pp. 694707, 2007.

[26] Z. Lim, J. L. Cheng, T. W. Lim et al., "Light activated disinfection: an alternative endodontic disinfection strategy," Australian Dental Journal, vol. 54, no. 2, pp. 108-114, 2009.

[27] S. Hirata, C. Kitamura, H. Fukushima et al., "Low-level laser irradiation enhances BMP-induced osteoblast differentiation by stimulating the BMP/Smad signaling pathway," Journal of Cellular Biochemistry, vol. 111, no. 6, pp. 1445-1452, 2010.

[28] G. L. Becker, S. Cohen, and R. Borer, "The sequelae of accidentally injecting sodium hypochlorite beyond the root apex: report of a case," Oral Surgery Oral Medicine and Oral Pathology, vol. 38, no. 4, pp. 633-638, 1974.

[29] R. E. Beltz, M. Torabinejad, and M. Pouresmail, "Quantitative analysis of the solubilizing action of MTAD, sodium hypochlorite, and EDTA on bovine pulp and dentin," Journal of Endodontics, vol. 29, no. 5, pp. 334-337, 2003.

[30] I. Heling, I. Rotstein, T. Dinur, Y. Szwec-Levine, and D. Steinberg, "Bactericidal and cytotoxic effects of sodium hypochlorite and sodium dichloroisocyanurate solutions in vitro," Journal of Endodontics, vol. 27, no. 4, pp. 278-280, 2001. 


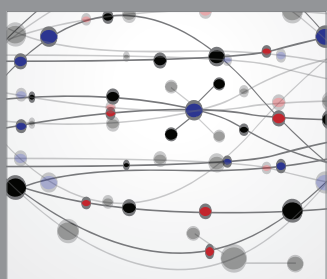

The Scientific World Journal
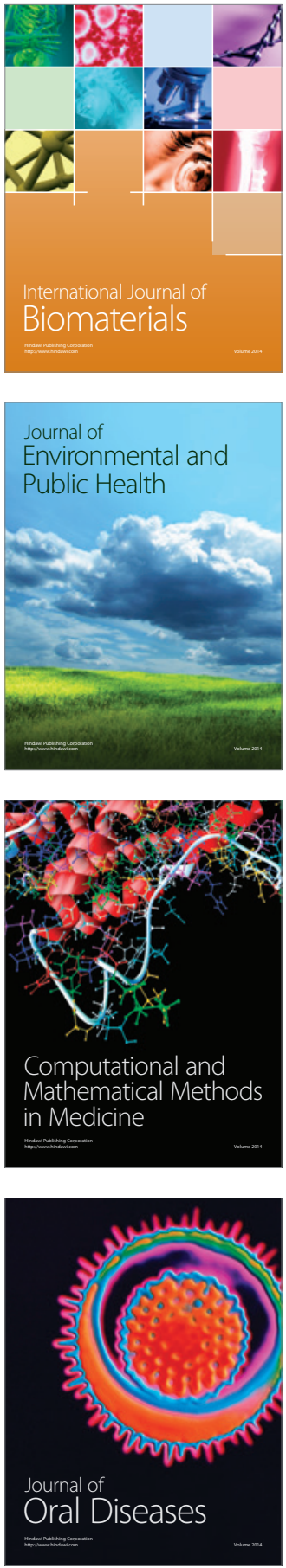
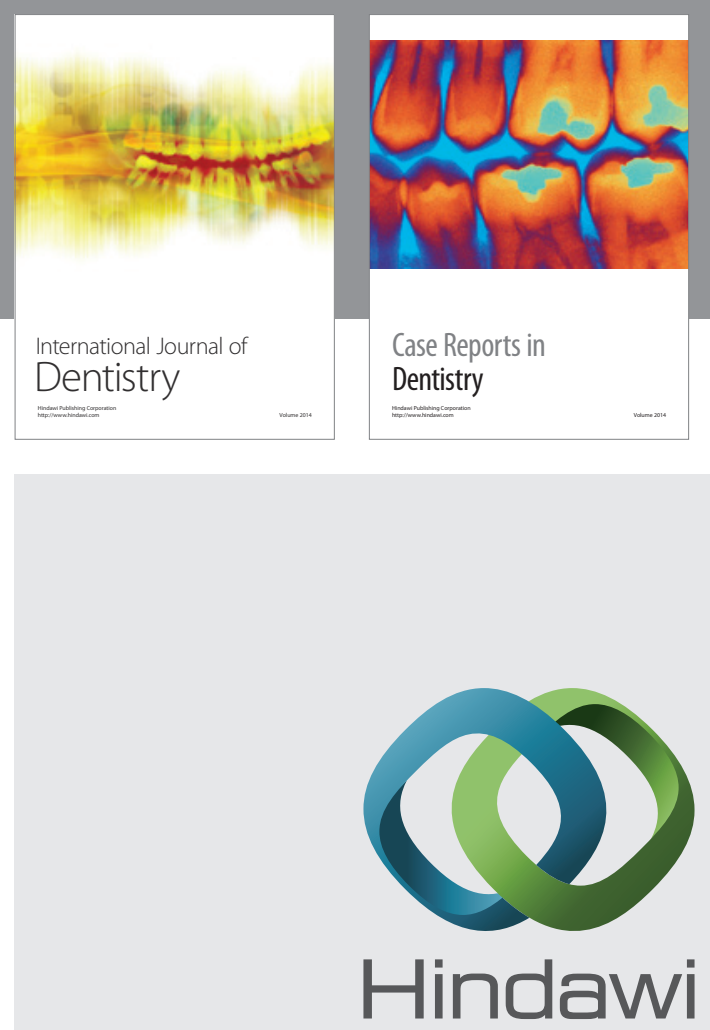

Submit your manuscripts at

http://www.hindawi.com
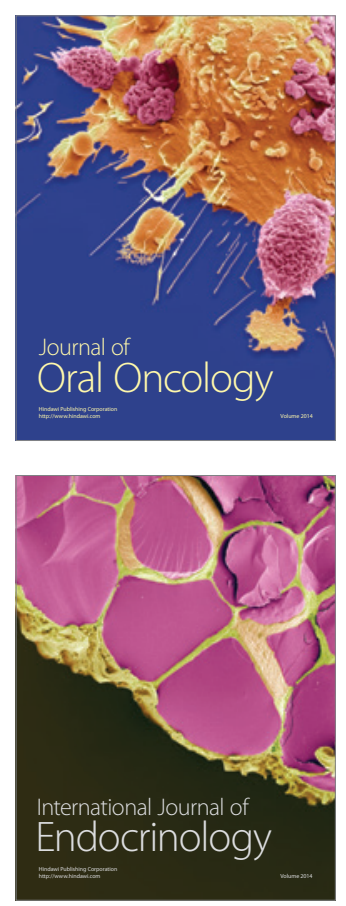
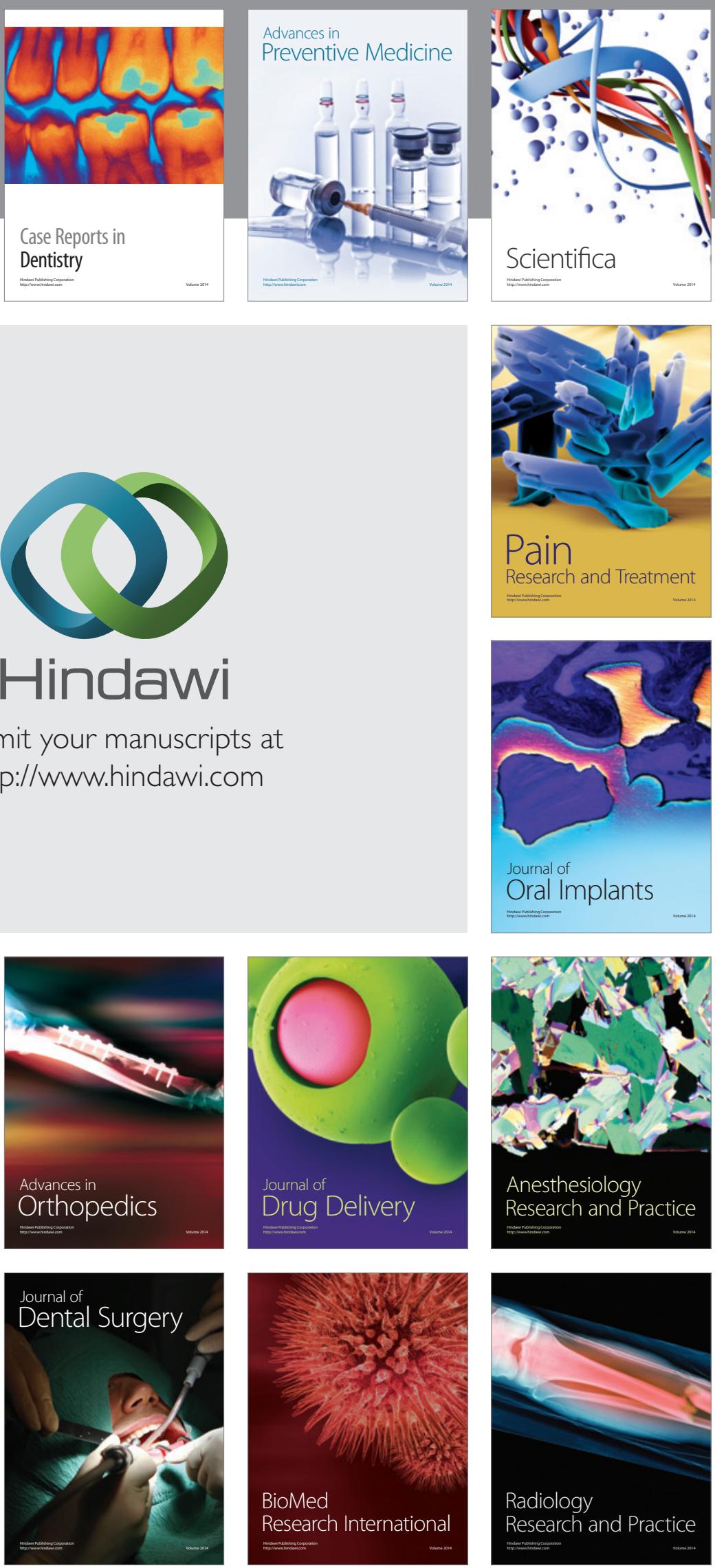